\title{
Calculation of Honeycomb Paperboard Resistance to Edge Crush Test
}

\author{
Gabriela Kmita-Fudalej ${ }^{1, *}$, Włodzimierz Szewczyk ${ }^{1}$ and Zbigniew Kołakowski ${ }^{2, *(\mathbb{D})}$ \\ 1 Centre of Papermaking and Printing, Lodz University of Technology, Wólczańska 223, 90-924 Lodz, Poland; \\ wlodzimierz.szewczyk@p.lodz.pl \\ 2 Department of Material Strength, Lodz University of Technology, Stefanowskiego 1/15, 90-924 Lodz, Poland \\ * Correspondence: gabriela.kmita-fudalej@dokt.p.lodz.pl (G.K.-F.); zbigniew.kolakowski@p.lodz.pl (Z.K.)
}

Received: 31 January 2020; Accepted: 3 April 2020; Published: 6 April 2020

\begin{abstract}
The article presents the method of calculating the edge crush test (ECT) of honeycomb paperboard. Calculations were made on the basis of mechanical properties of paper raw materials used for the production of cellular paperboard and geometrical parameters describing cellular paperboard. The presented method allows ECT calculation of honeycomb paperboard in the main directions in the paperboard plane; i.e., machine direction $(M D)$ and cross direction $(C D)$. The proposed method was verified by comparing the results of calculations with the results of $E C T$ measurements of paperboard with different geometrical parameters made of different fibrous materials.
\end{abstract}

Keywords: honeycomb paperboard; edge crush test; critical load; mechanical properties

\section{Introduction}

Honeycomb board is manufactured on the basis of fibrous materials, most often from coniferous trees. Due to the spatial structure, it has low specific weight and good strength properties $[1,2]$. Its advantages also include recyclability; excellent energy absorption properties; and insulation, thermal, and acoustic properties [3]. Honeycomb paper cores are used in many multilayer and packaging products and they successively replace this type of plastic or aluminium products due to the lower manufacturing cost and lower specific weight. This organic and biodegradable raw material is gaining great popularity in various industries. It is used as a fillings for doors, countertops, furniture boards, partition walls in construction, and sandwiched multilayer structures in the aviation and automotive industries [4-7]. The production and use of honeycomb paper panels in the furniture industry are developing rapidly in Europe [8]. The demand for lighter furniture elements is increasing, which is contributing to lower transport costs and easier assembly, alongside the reduction of formaldehyde emissions, which is also an important issue in the modern world [9].

In the packaging industry, cellular paperboard is used to produce large-size boxes and their fillings. In most applications, in which cellular paperboard is treated as a construction material, it carries compressive loads caused by forces acting in its plane. To assess strength at this type of load, its edge crush test, $E C T$, can be used. In a certain direction along the paperboard plane, the $E C T$ value is defined as the maximum compressive force transferred by the crushed paperboard until it is destroyed, related to the length of the side of the sample perpendicular to the direction of the force.

This indicator is particularly useful in cases wherein the strengths of panels with large values of panel thickness in the direction of load application are considered. This indicator is of decisive importance in, e.g., determining the resistance of boxes to the static pressure of boxes.

The study of cellular paperboard was carried out by Wen [10], who compared the results of measuring $5 \mathrm{~mm}$ thick cellular paperboard with the results of corrugated board. The comparison 
concerned both ECT edge crushing resistance in both directions in the paperboard plane, and the FCT flat crushing test.

Chen et al. [11] presented studies on lightweight multilayer panels with different honeycomb core structures made of paper, and wood cladding composite. By using experimental tests and finite element modelling methods, the authors presented the impacts of the construction parameters of honeycomb and the properties of the core material and cladding on the mechanical properties of light laminated panels.

Borsellino and Di Bella [12] conducted tests of laminates with different core structures at different load methods, including resistance to edge crushing of the paper honeycomb. The purpose of the work was based on experimental research to assess the relationship between stresses and deformations at uniform compressive static load.

Smardzewski et al. [13] conducted a study to determine the effect of a rectangular cellular paper core on the mechanical properties of three-layer furniture panels.

Smardzewski and Prekrat [14] presented modelling of mechanical properties of cellular wooden panels with a paper honeycomb core. The subjects of the study were the thin panels of a paper honeycomb with hexagonal cells. The research was carried out using numerical models; the results of numerical calculations were compared with the results of experimental measurements. As a result of the research, it was confirmed that the cores of cellular wood panels show strong orthotropic properties.

The authors of the work decided to develop a simple method for determining the ECT of honeycomb boards and to verify them in experimental studies. Another verification method was to develop complex numerical models in the finite element method (FEM), which should still be compared with experimental research.

Despite the fact that the literature provides information on ECT of honeycomb boards, none of the presented studies presents a simple, analytical method for determining the value of the edge crush resistance of cellular cardboard.

The purpose of the work is to present mathematical relationships that allow calculating the resistance of honeycomb paperboard to edge crushing in the machine and cross directions, based on its geometric parameters and mechanical properties of the materials from which it was made.

Cellular paperboard consists of two outer layers and a honeycomb core (see Figure 1).

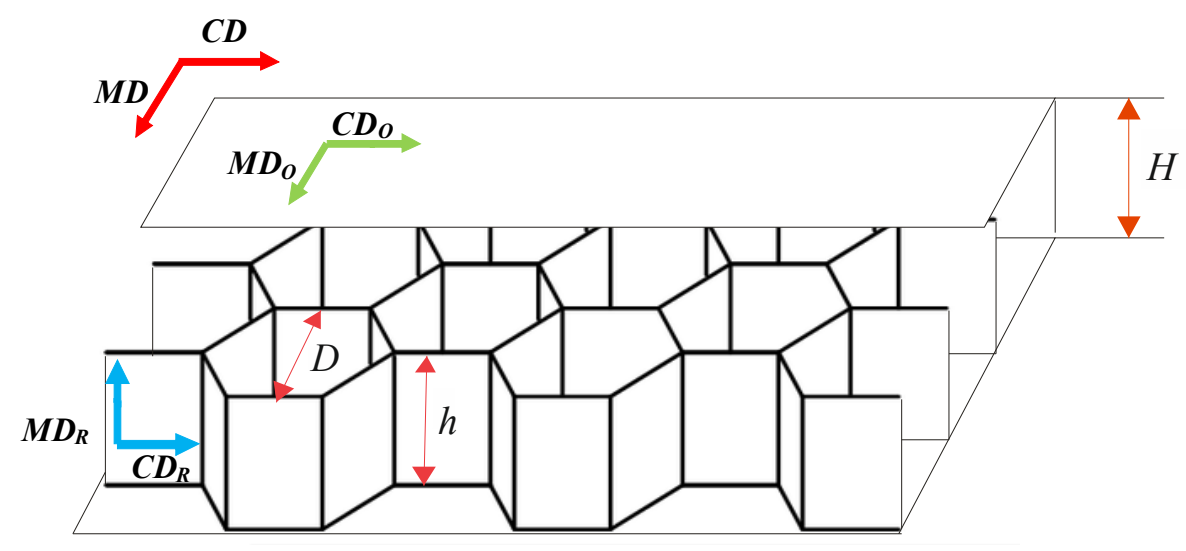

Figure 1. Cellular paperboard parameters.

The geometrical parameters describing the cellular paperboard are:

$D$-diameter of the circle inscribed in the regular hexagon determined by the contact lines of the cell walls with cover layer, defined as the cell mesh size;

$h$-core height;

$H$-paperboard thickness. 
The length of the regular hexagon's side can be determined from Equation (1) using parameter $D$ given by the paperboard manufacturer (see Figure 2):

$$
a=D / \sqrt{3}
$$

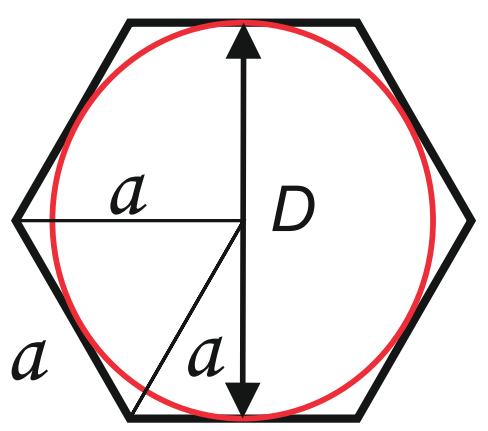

Figure 2. Cell mesh parameters.

Cellular cardboard has the characteristics of orthotropic bodies. This is due to the core structure and the distribution of mechanical properties of the flat layers, which is characteristic of orthotropic bodies. In the plane of cellular paperboard, two main directions of orthotropy can be distinguished. The first one coincides with the direction of manufacture and it is called machine direction, $M D$. The second main direction, perpendicular to the machine direction, is referred to as cross direction, $C D$. The main directions of the $C D$ and $M D$ of the paperboard coincide with the main directions of the paper used for the flat layers of the $C D_{O}$ and $M D_{O}$ paperboard (see Figure 1). In the case of a paperboard core, the machine direction of the paper used for the $M D_{R}$ core is parallel to the height of the core and the cross direction $C D_{R}$ is perpendicular to the height of the core.

The proposed method for determining the resistance of honeycomb paperboard to edge crushing is based on the stability of thin-walled isotropic [15-18] and orthotropic plates [19-23]. The formulas for calculating ECT presented in the article were developed in detail in [24-26].

\section{Materials and Methods}

Sixteen honeycomb paperboards with different geometrical parameters and made of different fibrous materials were tested, and 4 types of paper used for their production.

The following papers are used in the remainder of the article:

- T135-testliner, $135 \mathrm{~g} / \mathrm{m}^{2}$ basis weight;

- T160-testliner, $160 \mathrm{~g} / \mathrm{m}^{2}$ basis weight;

- T200-testliner, $200 \mathrm{~g} / \mathrm{m}^{2}$ basis weight;

- $\quad$ F140-fluting, $140 \mathrm{~g} / \mathrm{m}^{2}$ basis weight.

Table 1 presented material constants of the papers.

Table 1. Material constants of the papers are presented.

\begin{tabular}{cccc}
\hline Symbol & $\begin{array}{c}\text { Paper Thickness } \\
(\mathbf{m m})\end{array}$ & $\begin{array}{c}\text { Young's Modules of } \\
\text { Paper in Cross } \\
\text { Direction (GPa) }\end{array}$ & $\begin{array}{c}\text { Young's Modules of Paper in } \\
\text { Machine Direction } \\
\text { (GPa) }\end{array}$ \\
\hline T135 & 0.204 & 1.8 & 5.3 \\
T160 & 0.209 & 2.3 & 4.9 \\
T200 & 0.263 & 2.3 & 5.7 \\
F140 & 0.203 & 2.1 & 5.5 \\
\hline
\end{tabular}


The honeycomb paperboard markings contain information about their material composition according to the following record (material of the first cover layer/core material/material of the second cover layer). For example: honeycomb paperboard with the core made of T160 paper and two cover layers of T135 paper has the mark T135/T160/T135.

To identify each paperboard, thickness $H$, the diameter of the circle inscribed in the regular hexagon of the core $D$ cells, and the markings of the paper from which it was made, are provided.

To avoid the impact of climatic conditions on the results of strength tests of papers and boards, the testing pieces were conditioned before the test in accordance with PN-EN 20187: 2000 [27], and the tests were carried out in an air-conditioned room with the same climatic conditions as during the conditioning of the testing pieces; i.e., temperature $23 \pm 1{ }^{\circ} \mathrm{C}$ and relative air humidity $50 \% \pm 2 \%$.

In the case of paper from which paperboard was made, the basis weight was measured in accordance with PN-EN ISO 536: 2012 [28], thickness in accordance with PN-EN ISO 534: 2012 [29], and the Young's modulus in machine and cross directions was determined based on a tensile test at constant speed stretching performed in accordance with PN-EN ISO 1924-2: 2010 [30].

ECT measurements were made using a universal Zwick testing machine (Ulm, Germany) with a load range up to $20 \mathrm{kN}$ using the tooling shown in Figure 3. The tooling consists of two square plates of $144 \mathrm{~cm}^{2}$ each. Both plates are rigidly attached to the lower frame of the machine, and the upper to the movable traverse (see Figure 3a). Supporting blocks (see Figure 3b) were used to test cardboard with small thickness, maintaining the tested piece in a vertical position until reaching the initial force.

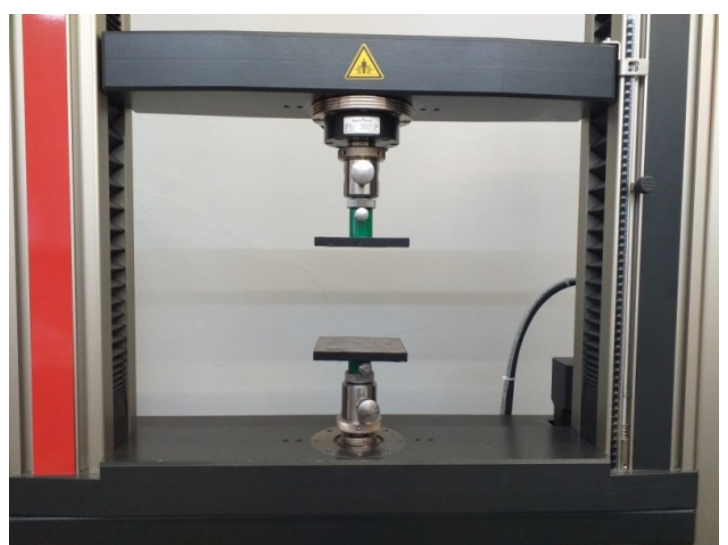

(a)

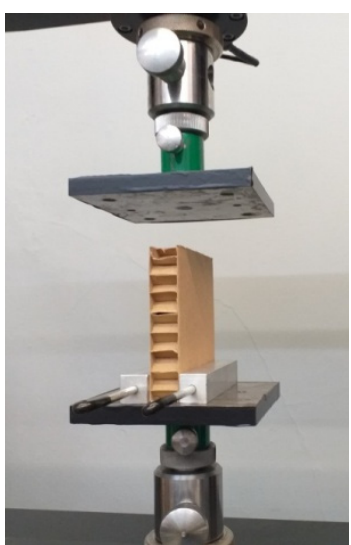

(b)

Figure 3. Instrumentation for the edge crush test (ECT): (a) measuring instrumentation; (b) test sample supported by support blocks.

One-hundred-millimetre squared tested pieces were crushed; only for paperboard less than $10 \mathrm{~mm}$ thick were the tested pieces reduced to $50 \mathrm{~mm}$ to protect against global buckling.

Before starting the measurement, the tested piece was subjected to a $10 \mathrm{~N}$ initial force. During the measurements, the plates approached each other at a speed of $12.5 \mathrm{~mm} / \mathrm{min}$.

The measurements were carried out in two main directions in the plane of the paperboard; and on their basis its resistance to edge crushing in the machine direction $E C T_{M D}$ and cross direction $E C T_{C D}$ was determined respectively. The result of the determination in each direction is given as the average value obtained after testing ten pieces.

The ECT value was calculated from the equation:

$$
E C T=\frac{F}{l}, k N / m
$$

where:

$\mathrm{F}$-value of destructive force, $\mathrm{kN}$; 
$l$ length of the loaded edge of the tested piece, $\mathrm{m}$.

\section{Calculation Methodology}

The resistance of cellular board, both in the machine direction and in the cross direction, was calculated as the sum of loads carried by the core and both cover layers:

$$
\begin{aligned}
& E C T_{M D}=E C T_{R M D}+E C T_{O M D} \\
& E C T_{C D}=E C T_{R C D}+E C T_{O C D}
\end{aligned}
$$

where:

$E C T_{R C D}$ and $E C T_{O C D}$ - edge crushing resistance towards $C D$, core and both cover layers, respectively, $E C T_{R M D}$ and $E C T_{O M D}$-resistance to edge crushing in the $M D$ direction of core and both cover layers, respectively.

It was assumed that the calculation model of the resistance to edge crushing of the core will describe the destruction of a repeating element of the paperboard core structure. The $A B C E$ periodic cell was separated from the honeycomb core structure (see Figure 4).

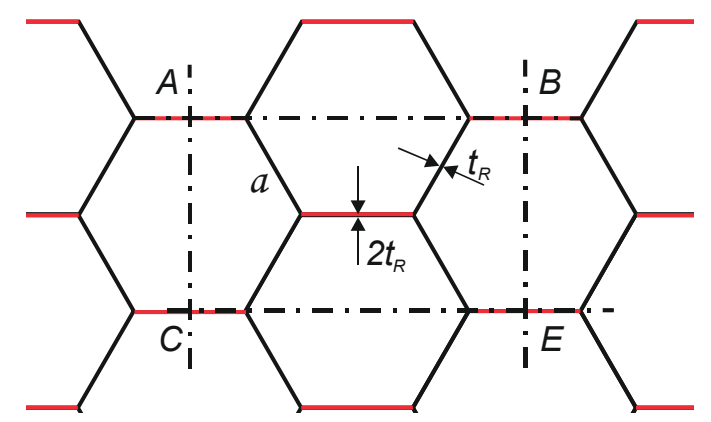

Figure 4. $A B C E$ periodic cell extracted from the paperboard core.

It has been assumed that the cross-section of the core cell with a plane parallel to the cover layer has the shape of a regular hexagon with side $a$.

Figure 5 shows the dimensions of the periodic cell.

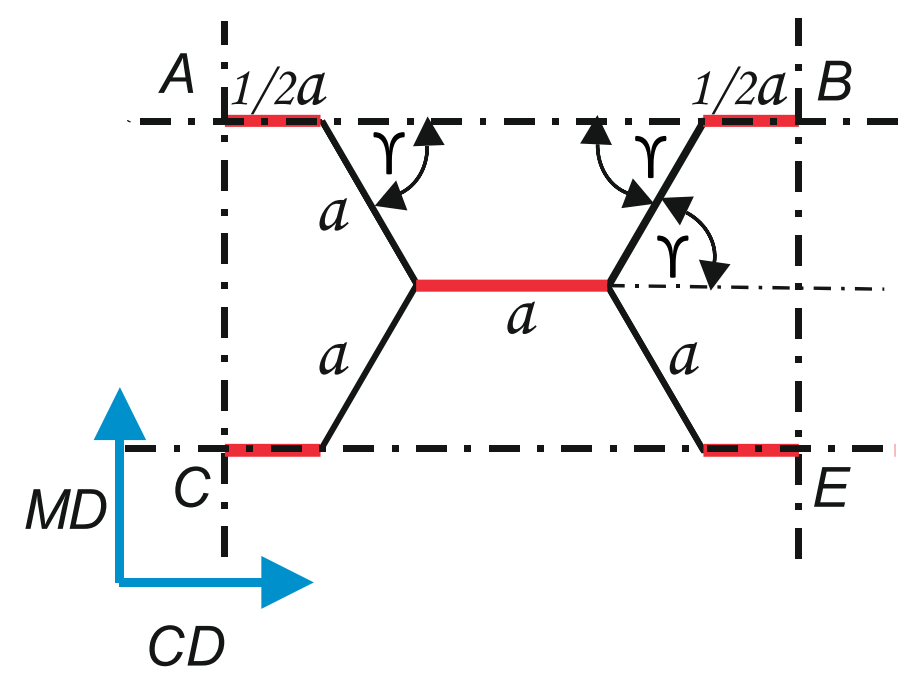

Figure 5. Dimensions of the periodic core cell. 
The dimensions of the periodic cell can be determined from the equation:

$$
\begin{gathered}
C E=A B=2 \cdot a+2 \cdot a \cdot \cos \gamma \\
A C=B E=2 \cdot a \cdot \sin \gamma
\end{gathered}
$$

In the case of a regular hexagon cell that has been taken into account in the calculations, the angle $\gamma$ is $60^{\circ}$. It was assumed that only single-thickness walls are responsible for cell destruction in the ECT test, $t_{R}$ marked in black in Figure 4 . The double walls $t_{R}$, which are formed by gluing two layers of core material marked in red in Figure 4, are not damaged, as observed in preliminary ECT tests of honeycomb panels.

The load schemes used to calculate the $Q$ forces transmitted through the periodic core cell in the $M D$ and $C D$ directions are illustrated in Figure 6.

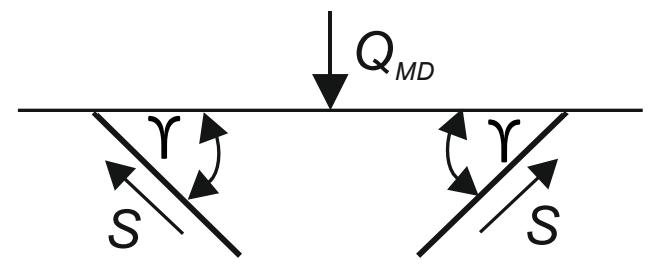

(a)

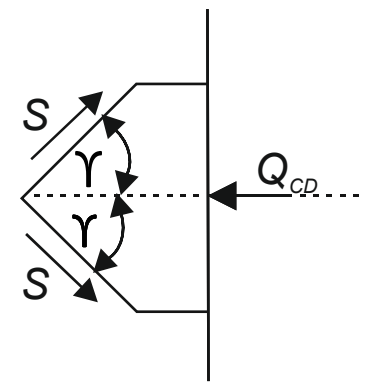

(b)

Figure 6. Load diagrams used to calculate $Q$ forces: (a) in machine direction $(M D)$, (b) towards cross direction $(C D)$.

The maximum $Q_{M D}$ and $Q_{C D}$ forces transferred by the periodic core cell in the $M D$ and $C D$ direction were calculated from:

$$
\begin{aligned}
& Q_{M D}=2 \cdot S \cdot \sin \gamma \\
& Q_{C D}=2 \cdot S \cdot \cos \gamma
\end{aligned}
$$

where:

$S$ - maximum force transmitted during compression in the cross direction of the core material by a wall of a single thickness.

The force $S$ can be determined from the following relationship:

$$
S=\alpha \cdot t_{R} \cdot h \cdot \sigma_{c r}
$$

where:

$t_{R}$-thickness of paper used for core production;

$h$-core thickness of cellular paperboard;

$\sigma_{\text {cr }}$-critical stress;

$\alpha$-coefficient of elastic restoration of a single cell wall.

The $\alpha$ factor is respectively:

$$
\begin{gathered}
\alpha=1.0 \text { gdy } \frac{a}{h}>1.0 \\
\alpha=3.41-1.41 \frac{a}{h} g d y \quad 0.2 \leq \frac{a}{h} \leq 1.0 \\
\alpha=1.0 \text { gdy } 0.1<\frac{a}{h}<0.2
\end{gathered}
$$


Critical stress $\sigma_{\mathrm{cr}}$ can be determined from the equation:

$$
\sigma_{c r}=\frac{\pi^{2} \cdot t_{R}^{2}}{12 \cdot h^{2}} \sqrt{E_{R M D} \cdot E_{R C D}}\left[\eta+2+\frac{1}{\eta}\right]
$$

where:

$$
\eta=\left(\frac{h}{a}\right)^{2} \cdot \sqrt{\frac{E_{\mathrm{RCD}}}{E_{\mathrm{RMD}}}}
$$

Substituting Equation (14) into Equation (13) gets:

$$
\sigma_{c r}=\frac{\pi^{2} \cdot t_{R}^{2}}{12 \cdot h^{2}} \cdot \sqrt{E_{R M D} \cdot E_{R C D}} \cdot\left[2+\left(\frac{h}{a}\right)^{2} \cdot \sqrt{\frac{E_{R C D}}{E_{R M D}}}+\frac{1}{\left(\frac{h}{a}\right)^{2} \cdot \sqrt{\frac{E_{R C D}}{E_{R M D}}}}\right]
$$

where:

$E_{R C D}, E_{R M D}-$ Young's paper moduli used to produce the cellular paperboard core in cross and machine directions, respectively.

Many studies are devoted to a detailed discussions of Equations (13) and (14), as presented by Kołakowski et al. [24-26].

The $E C T_{R M D}$ and $E C T_{R C D}$ core crush test was calculated from the relationship:

$$
\begin{aligned}
& E C T_{R M D}=\frac{Q_{M D}}{A B}=\frac{\alpha \cdot t_{R} \cdot h \cdot \sigma_{c r} \cdot \sin \gamma}{a \cdot(1+\cos \gamma)} \\
& E C T_{R C D}=\frac{Q_{C D}}{A C}=\frac{\alpha \cdot t_{R} \cdot h \cdot \sigma_{c r} \cdot \cos \gamma}{a \cdot \sin \gamma}
\end{aligned}
$$

The resistance of two honeycomb board cover layers to $E C T_{O M D}$ and $E C T_{O C D}$ edge crushing was determined from the following equation:

$$
\begin{gathered}
E C T_{O M D}=\beta_{O M D} \cdot \frac{2 \cdot \pi^{2} \cdot t_{o}^{3}}{3 \cdot(a+2 \cdot a \cdot \cos \gamma)^{2}} \cdot \sqrt{E_{O M D} \cdot E_{O C D}} \\
E C T_{O C D}=\beta_{O C D} \cdot \frac{\pi^{2} \cdot t_{o}^{3}}{6 \cdot(a \cdot \sin \gamma)^{2}} \cdot \sqrt{E_{O M D} \cdot E_{O C D}}
\end{gathered}
$$

where:

$E_{O C D}, E_{O M D}-$ Young's moduli of paper used to produce cover layers of cellular paperboard in cross and machine directions, respectively;

$t_{0}$-the thickness of the paper used for flat layers of cellular paperboard;

$\beta_{O M D}, \beta_{O C D}$-elastic support coefficients, determined experimentally.

It should be taken into account that $E_{O M D} \neq E_{O C D}$, and this implies that $\beta_{O M D} \neq \beta_{O C D}$.

The $\beta_{O M D}$ factor is assumed as a function of the $a / h$ ratio:

$$
\begin{gathered}
\frac{a}{h} \leq 0.6 \cdot \sqrt[4]{\frac{E_{O M D}}{E_{O C D}}} \text { to } \beta_{O M D}=1.1 \cdot \sqrt[4]{\frac{E_{O M D}}{E_{O C D}}} \\
\frac{a}{h}>0.6 \cdot \sqrt[4]{\frac{E_{O M D}}{E_{O C D}}} \text { to } \beta_{O M D}=\left[1.1+0.3 \cdot\left(\frac{a}{h}\right)\right] \cdot \sqrt[4]{\frac{E_{O M D}}{E_{O C D}}}
\end{gathered}
$$


The coefficient $\beta_{O C D}$ is constant, and it is:

$$
\beta_{O C D}=\left[1.5+0.6\left(\frac{a}{h}\right)\right] \cdot \sqrt[4]{\frac{E_{O C D}}{E_{O M D}}}
$$

The cellular board's resistance to edge crushing in the machine direction $E C T_{M D}$ and cross direction $E C T_{C D}$ can be determined from the Equations (23) and (24), obtained after substituting Equations (16) and (18) into Equations (3) and (17), and Equation (19) to Equation (4):

$$
\begin{gathered}
E C T_{M D}=E C T_{R M D}+E C T_{O M D}=\alpha \cdot \frac{t_{R} \cdot h \cdot \sigma_{c r} \cdot \sin \gamma}{a \cdot(1+\cos \gamma)}+\beta_{O M D} \cdot \frac{2 \cdot \pi^{2} \cdot t_{o}^{3}}{3 \cdot(a+2 \cdot a \cdot \cos \gamma)^{2}} \cdot \sqrt{E_{O M D} \cdot E_{O C D}} \\
E C T_{C D}=E C T_{R C D}+E C T_{O C D}=\alpha \cdot \frac{t_{R} \cdot h \cdot \sigma_{c r} \cdot \cos \gamma}{a \cdot \sin \gamma}+\beta_{O C D} \cdot \frac{\pi^{2} \cdot t_{o}^{3}}{6 \cdot(a \cdot \sin \gamma)^{2}} \cdot \sqrt{E_{O M D} \cdot E_{O C D}}
\end{gathered}
$$

\section{Results and Discussion}

Theoretical $E C T$ values in the machine direction $E C T_{M D}$ and cross direction $E C T_{C D}$ were calculated based on the results of measurements of the properties of the materials used for the production of cellular paperboards and the geometrical parameters of the boards.

\begin{tabular}{|c|c|c|c|c|c|c|c|c|c|c|}
\hline Symbol & $\begin{array}{c}D \\
\mathrm{~mm}\end{array}$ & $\begin{array}{c}H \\
\mathrm{~mm}\end{array}$ & $\begin{array}{c}E C T_{M D} \\
\mathrm{~N} / \mathrm{m}\end{array}$ & $\begin{array}{c}\text { Max } \\
E C T_{M D} \\
\text { N/m }\end{array}$ & $\begin{array}{c}\text { Min } \\
E C T_{M D} \\
\text { N/m }\end{array}$ & $\begin{array}{c}\mathrm{SD}_{\mathrm{MD}} \\
\mathrm{N} / \mathrm{m}\end{array}$ & $\begin{array}{c}E C T_{C D} \\
\mathrm{~N} / \mathrm{m}\end{array}$ & $\begin{array}{c}\text { Max } \\
E C T_{C D} \\
\text { N/m }\end{array}$ & $\begin{array}{c}\text { Min } \\
E C T_{C D} \\
\mathrm{~N} / \mathrm{m}\end{array}$ & $\begin{array}{c}\mathrm{SD}_{\mathrm{CD}} \\
\mathrm{N} / \mathrm{m}\end{array}$ \\
\hline T135/T135/T135 & 15 & 10 & 2235 & 2468 & 2061 & 115 & 2326 & 2429 & 2208 & 97 \\
\hline $\mathrm{T} 135 / \mathrm{T} 135 / \mathrm{T} 135$ & 15 & 15 & 2207 & 2362 & 2000 & 84 & 2389 & 2630 & 2110 & 215 \\
\hline T135/T135/T135 & 15 & 20 & 2270 & 2713 & 1854 & 306 & 2447 & 2629 & 2034 & 188 \\
\hline T135/T135/T135 & 15 & 30 & 2358 & 2630 & 1982 & 336 & 2457 & 2866 & 2016 & 340 \\
\hline $\mathrm{T} 135 / \mathrm{T} 160 / \mathrm{T} 135$ & 15 & 25 & 2138 & 2496 & 1900 & 182 & 2204 & 2337 & 2100 & 103 \\
\hline T135/T160/T135 & 15 & 35 & 2369 & 2555 & 2081 & 188 & 2454 & 2586 & 1897 & 182 \\
\hline $\mathrm{T} 135 / \mathrm{T} 160 / \mathrm{T} 135$ & 15 & 70 & 2464 & 2844 & 2136 & 217 & 2409 & 2608 & 2039 & 196 \\
\hline T200/F140/T200 & 15 & 20 & 2930 & 3706 & 2550 & 321 & 3334 & 3724 & 3005 & 391 \\
\hline T200/F140/T200 & 25 & 30 & 1378 & 1538 & 1169 & 118 & 1487 & 1665 & 1406 & 122 \\
\hline T200/F140/T200 & 25 & 40 & 1433 & 1891 & 1227 & 191 & 1417 & 1790 & 1089 & 276 \\
\hline
\end{tabular}

Tables 2 and 3 summarise the results of ECT measurements and calculations in both main directions.

Table 2. ECT measurement results: means of ten measurements and standard deviations. 
Table 3. ECT calculation results.

\begin{tabular}{|c|c|c|c|c|c|c|c|c|}
\hline Symbol & $\begin{array}{c}D \\
\mathrm{~mm}\end{array}$ & $\begin{array}{c}H \\
\mathbf{m m}\end{array}$ & $\begin{array}{c}E C T_{M D} \\
\mathrm{~N} / \mathrm{m}\end{array}$ & $\begin{array}{c}\text { Max } \\
E C T_{M D} \\
\mathrm{~N} / \mathrm{m}\end{array}$ & $\begin{array}{c}\text { Min } \\
E C T_{M D} \\
\mathrm{~N} / \mathrm{m}\end{array}$ & $\begin{array}{c}E C T_{C D} \\
\mathbf{N} / \mathrm{m}\end{array}$ & $\begin{array}{c}\text { Max } \\
E C T_{C D} \\
\mathrm{~N} / \mathrm{m}\end{array}$ & $\begin{array}{c}\text { Min } \\
E C T_{C D} \\
\mathrm{~N} / \mathrm{m}\end{array}$ \\
\hline T135/T135/T135 & 15 & 8 & 1989 & 2434 & 1692 & 2200 & 2675 & 1928 \\
\hline T135/T135/T135 & 15 & 10 & 2373 & 2897 & 2033 & 2554 & 3105 & 2240 \\
\hline T135/T135/T135 & 15 & 15 & 1932 & 2353 & 1675 & 2207 & 2679 & 1956 \\
\hline T135/T135/T135 & 15 & 20 & 1942 & 2363 & 1697 & 2163 & 2624 & 1929 \\
\hline T135/T135/T135 & 15 & 28 & 2111 & 2564 & 1859 & 2286 & 2771 & 2051 \\
\hline T135/T135/T135 & 15 & 30 & 2166 & 2631 & 1911 & 2334 & 2828 & 2096 \\
\hline T135/T160/T135 & 15 & 25 & 2436 & 2968 & 2080 & 2625 & 3191 & 2285 \\
\hline T135/T160/T135 & 15 & 35 & 2856 & 3476 & 2442 & 3010 & 3656 & 2615 \\
\hline T135/T160/T135 & 15 & 70 & 2004 & 2439 & 1712 & 2111 & 2563 & 1844 \\
\hline T200/F140/T200 & 15 & 20 & 3265 & 3780 & 2803 & 4040 & 4665 & 3485 \\
\hline T200/F140/T200 & 15 & 30 & 3539 & 4106 & 3028 & 4171 & 4828 & 3584 \\
\hline T200/F140/T200 & 15 & 50 & 2742 & 3165 & 2374 & 3261 & 3756 & 2830 \\
\hline T200/F140/T200 & 15 & 60 & 2864 & 3309 & 2474 & 3355 & 3869 & 2905 \\
\hline T200/F140/T200 & 21 & 20 & 1654 & 1915 & 1421 & 2136 & 2464 & 1845 \\
\hline T200/F140/T200 & 25 & 30 & 1166 & 1350 & 1002 & 1460 & 1686 & 1261 \\
\hline T200/F140/T200 & 25 & 40 & 1209 & 1402 & 1037 & 1461 & 1690 & 1259 \\
\hline
\end{tabular}

Figures 7 and 8 show a comparison of measurement results and calculations of cellular board resistance to edge crushing in the machine and cross directions.

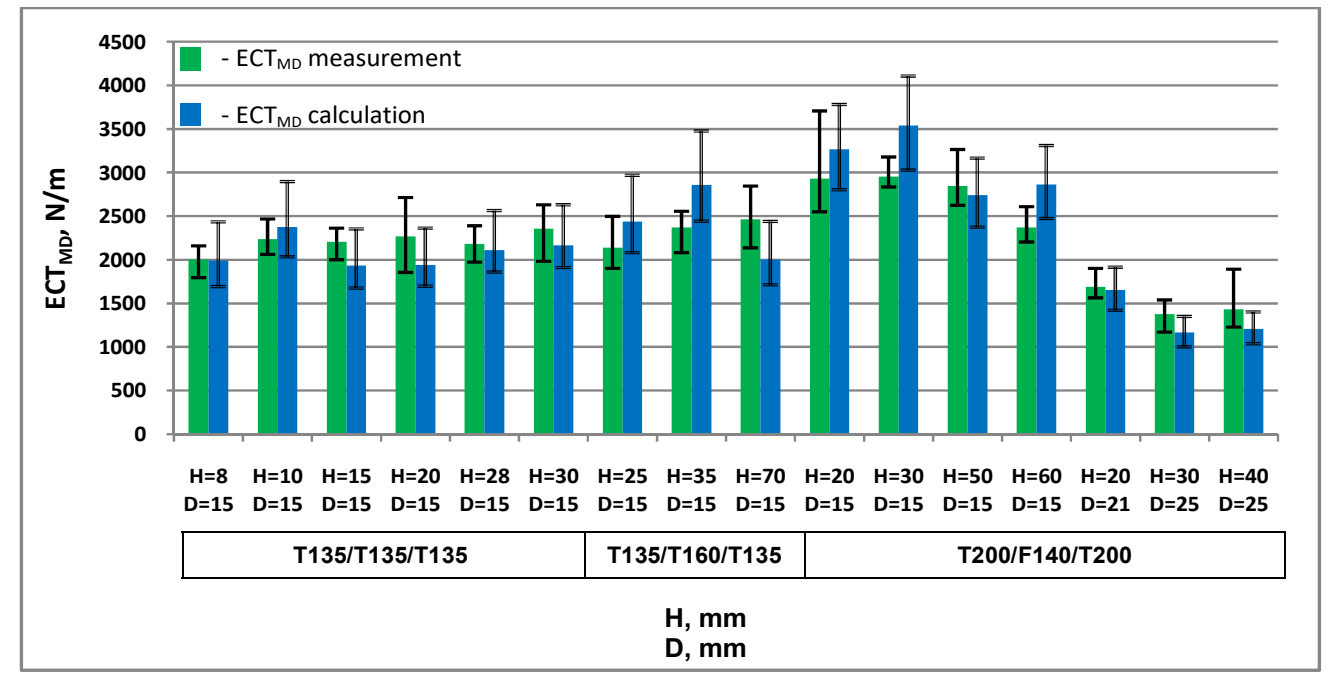

Figure 7. Resistance of honeycomb paperboard to edge crushing in the machine direction. 


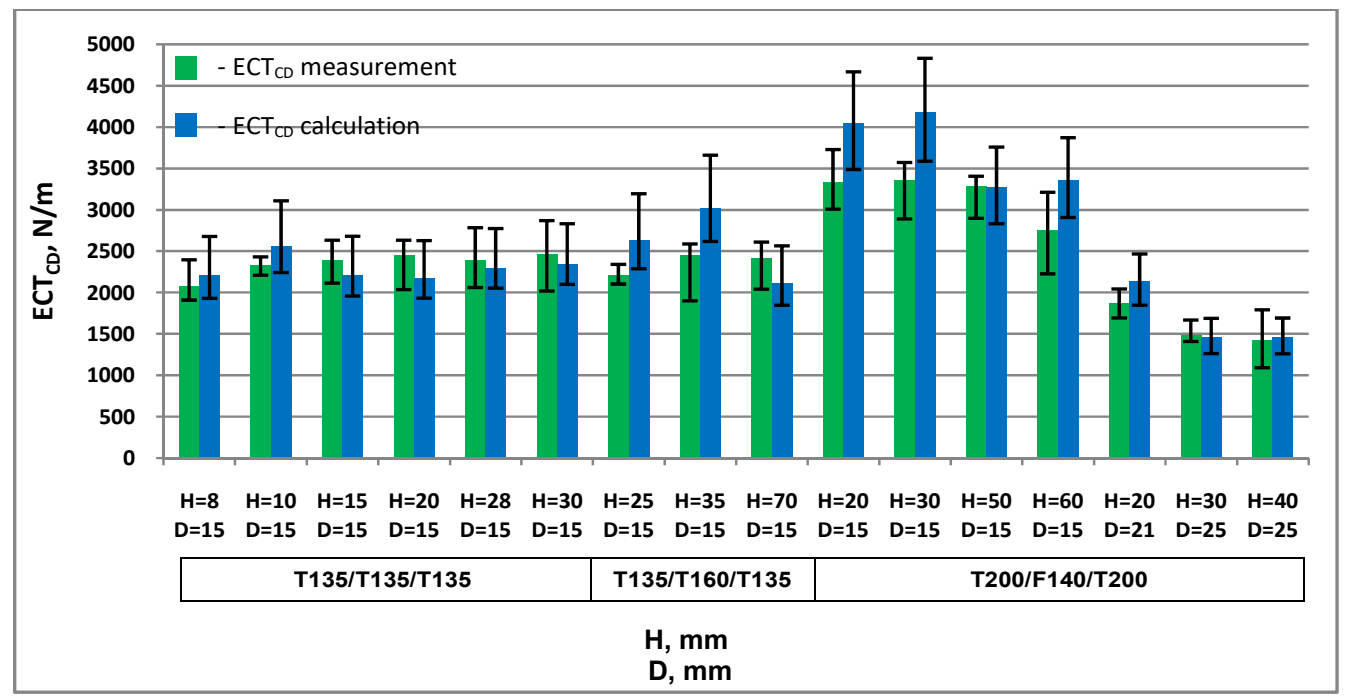

Figure 8. Resistance of honeycomb paperboard to edge crushing in the cross direction.

In almost all cases examined, the differences between the measured and calculated ECT values are within the variability of the results of measurements and calculations. For two honeycomb paperboards, the minimum calculation value is greater than the maximum value obtained from measurements by less than $1.2 \%$.

The largest discrepancy between the measured and calculated values was in the $M D$ direction: $20 \%$ of the actual $E C T_{M D}$ value and in the $C D$ direction $24 \%$. The largest $E C T_{M D}$ discrepancy was found in the case of cardboard with mesh size $D=15 \mathrm{~mm}$, thickness $H=60 \mathrm{~mm}$, made of T200 and F140 papers. The largest discrepancy between the calculated and measured $E C T_{C D}$ values was in the case of paperboard with mesh size $D=15 \mathrm{~mm}$, thickness $H$ equal to $30 \mathrm{~mm}$, made of T200 and F140 papers. The mean value of the discrepancy between the measured and calculated ECT values in all the cases examined was $11 \%$ of the actual value in both $M D$ and $C D$.

Figure 9 summarizes the ECT measurements of paperboard with the same mesh size made of the same materials.

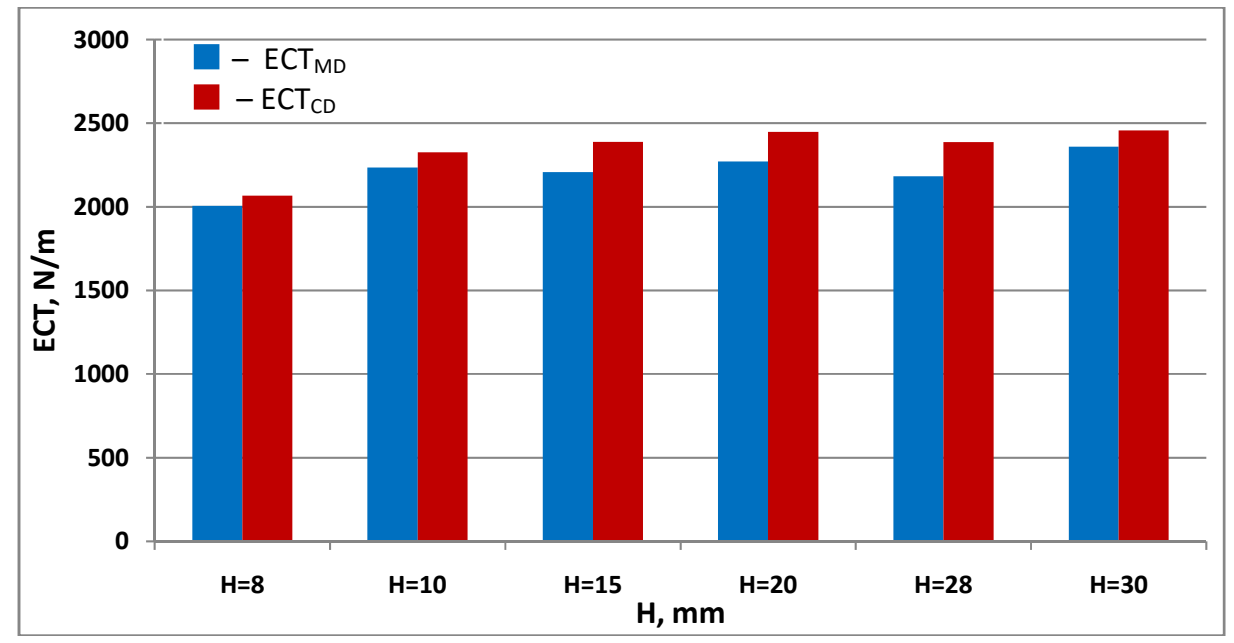

Figure 9. Results of $E C T_{M D}$ and $E C T_{C D}$ measurements of paperboard with $15 \mathrm{~mm}$ mesh diameter, made of T135 paper.

In both cases, at low core heights, up to $20 \mathrm{~mm}$, there is an increasing tendency for greater edge crush resistance as the cardboard thickness increases. Then, the ECT value remains at the same level. 
This is due to the fact that as the value of the $a / h$ decreases, the influence of the core on the ECT of the paperboard decreases, striving for a constant value.

Figure 10 shows ECT values of cardboard with the same geometrical parameters made of various raw fibres.

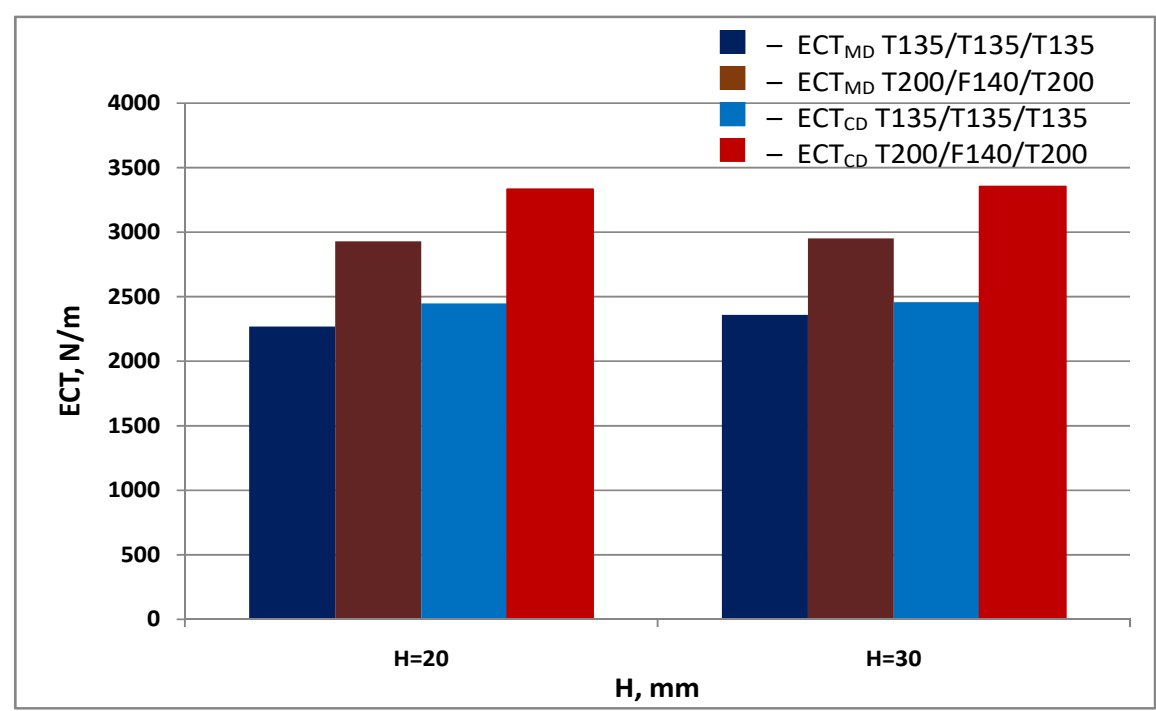

Figure 10. Results of $E C T_{M D}$ measurements of cardboard with a $15 \mathrm{~mm}$ mesh diameter, made of various raw materials.

The measurement results illustrated in Figure 10 show the effect of physical properties of the papers on the ECT of cellular board. The use of a paper with a higher basis weight, and thus higher thickness and better mechanical properties, causes a significant increase in the ECT value in both machine and cross directions.

Figures 11 and 12 show ECT values of paperboard made from the same raw materials of the same thickness, differing in mesh size.

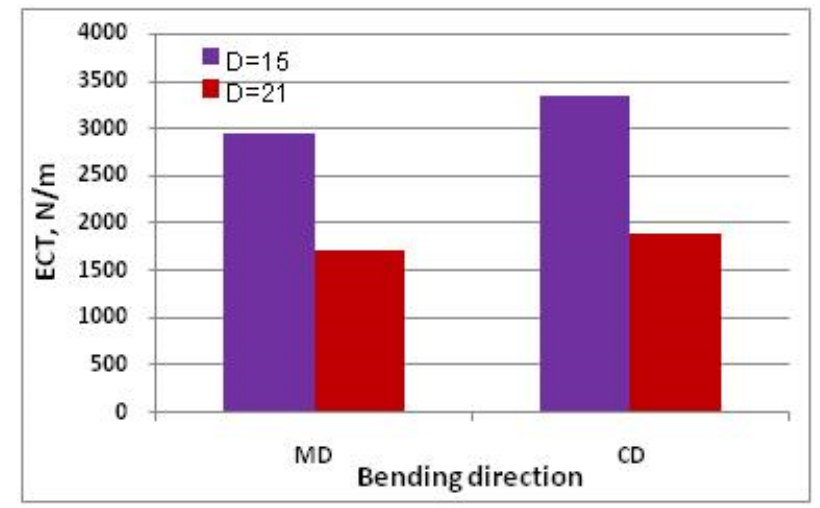

Figure 11. ECT of paperboard with thickness $H=20$ and different mesh sizes, made of paper T200/F140/T200. 


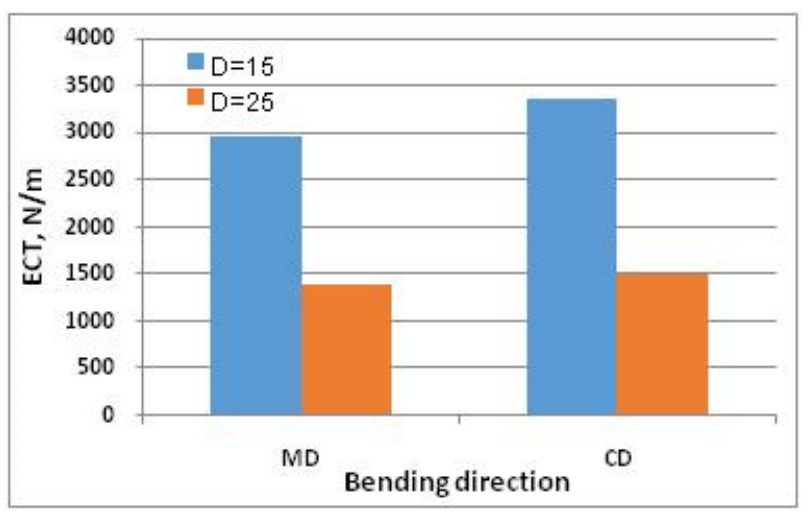

Figure 12. ECT of paperboard with thickness $H=30$ and different mesh sizes, made of T200/F140/T200 papers.

The very large decrease in ECT of cellular board visible in Figures 11 and 12 is associated with a decrease in the force transmitted by the cover layers, which buckle more easily with an increase in mesh size.

The relationships between the individual parameters used to calculate ECT and its value show a consistent nature with the mathematical relationships presented in Equations (23) and (24); e.g., an increase in cardboard thickness causes an increase in ECT value, while an increase in mesh size causes a decrease in ECT value.

The big impact on the differences between the real values of edge crush resistance and the values calculated in theoretical way result from the fact that the paperboard was produced in different periods of time, and during the production of the core, the papers are unwound simultaneously from several turns, and thus for their production, materials from various supplies are used, the mechanical properties of which may differ significantly. It happens that the actual values of mechanical properties differ by up to $20 \%$ from the nominal values given in the specification. In addition, switching machines for the production of paperboard of a different thickness can cause a different degree of stretching of the core or a different arrangement of the cell wall gluing lines, and thus the deviation of the dimensions and shape of the cell from the cells shaped like a hexagon, which is the shape adopted in the mathematical description. Very often during production, the core is slightly crushed, which also has a significant impact on the value of edge crush resistance [31].

During the tests, no global buckling of paperboard samples was found. Shibao Wen [10], who tested much thinner (and thus more vulnerable to global buckling) cellular cardboard with a thickness of about $5 \mathrm{~mm}$ did not find this phenomenon.

\section{Conclusions}

The proposed method allows one to calculate the ECT of cellular paperboard both in machine and cross directions on the basis of the paperboard's geometric parameters and the mechanical properties of materials used for its production. It is much easier and much faster in practical application than numerical methods such as the finite element method or the finite difference method. In the examined range of $a / h$ values in each of the main directions in the board plane, the theoretically calculated values differed from real values by an average of $11 \%$ of the actual value, and the maximum difference that occurred in the cross direction was $24 \%$. Considering that the mechanical properties of raw materials and the geometrical parameters of paperboard can differ significantly from the nominal values assumed during the calculations, the obtained calculation accuracy can be considered satisfactory. In the future, the authors plan to compare the results obtained with the proposed calculation method and the results obtained by numerical calculations. However, they do not expect significant differences in the accuracy of the calculations due to the fact that the calculation errors result from the variability of strength 
properties of materials and heterogeneity of the geometry of the core due to changes in the parameters of the production process.

Author Contributions: Conceptualization, Z.K., W.S., and G.K.-F.; methodology, Z.K., G.K.-F., and W.S.; conceived and designed the experiments G.K.-F. and W.S.; prepared the materials and samples, G.K.-F.; performed the experiments as part of her doctoral thesis, G.K.-F.; processed and collated the results, G.K.-F., All authors have read and agreed to the published version of the manuscript.

Funding: This research received no external funding.

Conflicts of Interest: The authors declare no conflict of interest.

\section{References}

1. Barboutis, I.; Vassiliou, V. Strength Properties of Lightweight Paper Honeycomb Panels for the Furniture; Aristotle University of Thessaloniki, Faculty of Forestry and Natural Environment: Thessaloniki, Greece, 2005.

2. Sam-Brew, S.; Semple, K.; Smith, G. Preliminary experiments on the manufacture of hollow core composite panels. For. Prod. J. 2011, 61, 381-389. [CrossRef]

3. Bitzer, T. Honeycomb Technology-Materials, Design, Manufacturing, Applications and Testing; Chapman \& Hall: London, UK, 1997.

4. Davies, J.M. Lightweight Sandwich Construction. Published on Behalf of CIB Working Commission. W056 Sandwich Panels (Joint CIB-ECCS Commission); Blackwell Science: Oxford, UK, 2001; 370p.

5. Fell, D. Trend Spotting: Doors. Woodworking. 2008, 22, p. 10. Available online: www.woodworkingcanada. com (accessed on 4 August 2015).

6. Wernuld, G. Wood Goes "High Tech" Finally: Honeycomb Panels Offer Performance, Design Flexibility and, Most Importantly, Much Lighter Weight, Wood \& Wood Products 2004; Vance Publishing Corporation: Lincolnshire, IL, USA, 2004.

7. Paul, R.; Klusmeier, W. Structhan $®-A$ Composite with a Future; Status Report; Bayer AG: Leverkusen, Germany, 1997.

8. Stosch, M. Think Light. Innovative Lightweight Panels, Seminar, Sheraton Vancouver Guilford Hotel, Surrey, Canada, 11 March 2008, University of Applied Sciences, Lippe/Höxter, Germany; KonradinVerlag: Leinfelden-Echterdingen, Germany, 2008; 103p.

9. Wisdom, B.B. Think "Better"-Lightweight Panel Advantages Driver Its Momentum. Modern Woodworking. 2005. Advanced Processing Technology and Management: 14-15. Available online: www.modernwoodworking.com (accessed on 23 November 2011).

10. Wen, S. Compressive Performance Investigation between Thin Honeycomb Paperboard and Corrugated Paperboard of Flute A. Adv. Mater. Res. 2012, 487, 198-202. [CrossRef]

11. Chen, Z.; Yan, N.; Sam-Brew, S.; Smith, G.; Deng, J. Investigation of mechanical properties of sandwich panels made of paper honeycomb core and Wood composite skins by experimental testing and finite element (FE) model ling methods. Eur. J. Wood Wood Prod. 2014, 72, 311-319. [CrossRef]

12. Borsellino, C.; Di Bella, G. Paper-Reinforced Biomimetic Cellular Structures for Automotive Applications. Mater. Des. 2009, 30, 4054-4059. [CrossRef]

13. Smardzewski, J.; Gajęcki, A.; Wojnowska, M. Investigation of elastic properties of paper honeycomb panels with rectangular cells. BioResources 2019, 14, 1435-1451.

14. Smardzewski, J.; Prekrat, S. Modelling of thin paper honeycomb panels for furniture. In Proceedings of the International Conference Ambienta, Wood is Good-With Knowledge and Technology to a Competitive Forestry and Wood Technology Sector, Zagreb, Croatia, 12 October 2012; pp. 179-186.

15. Brzoska, Z. Statics and Stability of Beam and Thin-Walled Structures; PWN (Polish Scientific Publishers): Warsaw, Poland, 1965. (In Polish)

16. Gere, J.M. Mechanics of Materials, 6th ed.; Brooks/Cole-Thomson Learning, Inc.: Belmont, CA, USA, 2004.

17. Krolak, M. (Ed.) Post-Buckling Behaviour and Load Carrying Capacity of Thin-Walled Plate Girders; PWN (Polish Scientific Publishers): Warsaw-Lodz, Poland, 1990. (In Polish)

18. Timoshenko, S.; Woinowsky-Kriegier, S. Theory of Plates and Shells; Mc Graw-Hill Book Company Inc.: New York, NY, USA; Toronto, ON, Canada; London, UK, 1959. 
19. Altenbach, H.; Altenbach, J.; Kissing, W. Structural Analysis of Laminate and Sandwich Beams and Plates. An Introduction into the Mechanics of Composite; Lublin Scientific Society: Lublin, Poland, 2001.

20. Altenbach, H.; Altenbach, J.; Kissing, W. Mechanics of Composite Structural Elements; Springer: Berlin/Heidelberg, Germany, 2004.

21. Carlsson, L.A.; Byron Pipes, R. Experimental Characterization of Advanced Composite Materials; CRC Press: Lancaster, UK, 1997.

22. Jones, R.M. Mechanics of Composite Materials, 2nd ed.; Taylor\&Francis: Boca Raton, FL, USA, 1999.

23. Kolakowski, Z.; Krolak, M.; Kowal-Michalska, K. Modal interactive buckling of thin-walled composite beam-columns regarding distortional deformations. Int. J. Eng. Sci. 1999, 37, 1577-1596. [CrossRef]

24. Kołakowski, Z.; Łęcka, M.; Mania, R.; Marynowski, K. Forecasting of the corrugated board buckling based on the ECT and BCT indexes. Theor. Found. Civ. Eng. Pol. Ukr. Trans. 2004, 12, 213-220.

25. Kołakowski, Z.; Mania, R.; Łęcka, M.; Marynowski, K. New closed forecasting method of the ECT and BCT indexes of papermaking products. Theor. Found. Civ. Eng. Pol. Ukr. Lith. Trans. 2006, 14, 131-138.

26. Kołakowski, Z.; Mania, R. Closed method of lower bound estimation of the BCT index. Opakowanie 2007, 7, $49-52$.

27. SAI Global. PN-EN 20187:2000: Paper, Board and Pulps—Standard Atmosphere for Conditioning and Testing and Procedure for Monitoring the Atmosphere and Conditioning of Samples; SAI Global: Sydney, Australia, 2000.

28. SAI Global. PN-EN 536:2012: Paper and Board-Determination of Grammage; SAI Global: Sydney, Australia, 2012.

29. SAI Global. PN-EN ISO 534:2012: Paper and Board—Determination of Thickness, Density and Specific Volume; SAI Global: Sydney, Australia, 2012.

30. SAI Global. PN-EN ISO 1924-2:2010: Paper and Board—Determination of Tensile Properties—Part 2: Constant Rate of Elongation Method (20 mm/min); SAI Global: Sydney, Australia, 2010.

31. Gaydachuk, A.V.; Slivinsky, M.V.; Golovanevsky, V.A. Technological Defects Classification System for Sandwiched Honeycomb Composite Materials Structures. Mater. Forum 2006, 30, 96-102.

(C) 2020 by the authors. Licensee MDPI, Basel, Switzerland. This article is an open access article distributed under the terms and conditions of the Creative Commons Attribution (CC BY) license (http://creativecommons.org/licenses/by/4.0/). 